\title{
Application of Well-Known Antiviral Drugs in the Field Formed by the Unexplained Properties of Low-Level Laser Radiation in Therapy of Covid-19 and Chronic Viral Hepatitis
}

\author{
Naylya Djumaeva \\ Out-Patient Department of the Virology Research Institute, Tashkent, Uzbekistan \\ Email: naila.djumaeva@gmail.com
}

How to cite this paper: Djumaeva, N. (2021) Application of Well-Known Antiviral Drugs in the Field Formed by the Unexplained Properties of Low-Level Laser Radiation in Therapy of Covid-19 and Chronic Viral Hepatitis. Optics and Photonics Journal, 11, 430440.

https://doi.org/10.4236/opj.2021.119031

Received: August 22, 2021

Accepted: September 24, 2021

Published: September 27, 2021

Copyright $\odot 2021$ by author(s) and Scientific Research Publishing Inc. This work is licensed under the Creative Commons Attribution International License (CC BY 4.0).

http://creativecommons.org/licenses/by/4.0/

(c) (i) Open Access

\begin{abstract}
Low-level laser therapy (LLLT) or cold laser has been used in medicine for several decades. However, the method utilizes a direct contact of the light beam with a patient. Further research resulted in development of another method that enables remote transmission of the pharmacological properties of a medicament into a human body with the application of low-level laser radiation as the light source. 18 patients with different viral diseases were treated with the antiviral drugs placed into the field formed by the unexplained properties of low-level laser radiation of the "device for transfer of the pharmacological properties of a drug into the patient's body". This resulted in improvement of the patient's condition, the absence of side effects and adverse reactions when using drugs in the proposed device and shortened therapy period for patients with chronic hepatitis $\mathrm{C}$ infection and Covid-19 patients. The long-term follow-up of the patients with chronic hepatitis B infection showed that hepatitis $B$ virus remained at low replication levels under the influence of the therapy, which made it possible to avoid such formidable complications of the disease as cirrhosis of the liver and liver cancer.
\end{abstract}

\section{Keywords}

Low-Level Laser Radiation, Device for Transfer of Pharmacological Properties of a Drug into a Patient's Body, Laser-Light Guide Emitter, Chronic Viral Diseases, Covid-19 


\section{Introduction}

Low-level laser therapy (LLLT) in the visible to near infrared spectral band (390 $1100 \mathrm{~nm}$ ) is absorption of laser light at the electronic level, without generation of heat.). Laser is a device, which produces intense, monochromatic, coherent, and highly collimated beam of light [1]. Numerous studies have shown that underlying mechanisms of beneficial impact of lasers to patients involves biological processes at the cellular and molecular levels. The biological effects of LLLT at the cellular and molecular level could include cellular viability, induction of autologous bone-marrow stem cells, proliferation rate, as well as DNA integrity and the repair of damaged DNA [2] [3]. LLLT can prevent cell apoptosis [4], stimulation of mitochondrial activity, increased cell turnover, recruitment and proliferation, modulation of the cellular metabolites [5]. It was suggested that LLLT might promote changes in the cellular redox state, playing an important role in sustaining cellular activities and inducing photo-biostimulative processes [6]. In addition to the above, preexposure of LLLT had a protective effect against many external agents such as hydrogen peroxide $\left(\mathrm{H}_{2} \mathrm{O}_{2}\right)$ and $\mathrm{UV}$ radiation [7]. In chronic viral diseases the laser therapy provides compensation for NO deficiency, which increases the overall defense of the body against free radicals and reduces the severity of oxidative stress [8]. Although various studies included hypotheses explaining the mechanisms of laser action on biological systems, the understanding of the biological effects of laser therapy is still poor.

Treatment of chronic viral liver disease includes the use of different antiviral drugs. Despite significant advances in the therapy of viral pathology in recent years, the use of known antiviral drugs is associated with the need for their longterm use, the presence of side effects, adverse reactions and special instructions when using them. Long-term searches associated with alternative approaches to the use of drugs in the treatment of patients with chronic pathology led the author of the article to applying the "device for remote transfer of information from the medicine to the human body" (DTIM) [9].

The questions that the researcher faced were as follows:

1) How safe is the use of well-known antiviral drugs placed into the field of the DTIM in the treatment of chronic viral liver disease's patients?

2) How long do the effects of the therapy perform using the DTIM?

The following goals were set:

3) Show that this approach to the use of known antiviral drugs in a group of patients with chronic liver pathologies ensures long-term remission of the disease and thus prevents the development of formidable complications of the disease such as liver cirrhosis and cancer of the liver.

4) Show that the use of a well-known antiviral drug in the field of the DTIM in a group of patients with Covid-19 is safe and contributes to the rapid recovery of the patients.

This article describes the original use of low-level laser radiation with no direct contact of the laser beam on the patient. This approach to the use of drugs 
allows to quickly and safely obtain the desired antiviral effect from the use of an antiviral drug in the field of the emitter that differs it from the traditional use of drugs in tablets or injection form administered to the patient. The article might gain the attention of specialists in laser optic so they that study the unusual properties of low-level lasers, which apparently maximally manifest themselves, provided that the laser beam makes a full turn around its axis, forming a cycle. Then the cylinder is formed as a result of the formation of a series of circles created from the fiber optic waveguide. When the laser is switched on, a certain field is formed inside the cylinder, which has a number of properties, including the ability of this field to remote transfer the properties of a drug placed in the field over a distance.

\section{Materials and Methods}

The Ethic Committee of the Ministry of Health of Uzbekistan approved the study. The examination and observation of the patients has been conducted in the Out-Patient Department of the Institute of Virology of the Ministry of Health of Uzbekistan. Eighteen patients took part in the study: 3 CHBV patients, 3 CHCV patients and 12 patients with Covid-19 infection. All patients signed the informed consent form.

\subsection{Equipment}

To transfer pharmacological properties from medicine to patients' body the "device for remote transfer information from medicine to human body" has been used. This device is described in a patent of Russian scientists of the Institute of Space Anthropo-ecology of Siberian Branch of the Academy of Science of Russia [9]. The device includes a hollow closed cylinder with cover made from non-electro-conductive substance round which, on the lateral surface, a lightguide fiber optic is spiraled and connected to a light source. A medicine is placed into the cylinder. The patent of the Russian Federation proposes to use a helium-neon laser as a light source. We used a semiconductor laser with the wave length of the electromagnetic component of emission equal to $650 \mathrm{~nm}$ while the average capacity is $5 \mathrm{~mW}$. At first, laser device turns on and the device prepares to functioning for three minutes. After that, the cylinder is situated on the patient's body above the affected organ or the pathological process focus, and the drug is placed into the cylinder and cylinder is closed with the cover. The drug's doses corresponded to the ones recommended for the specific disease. The pharmacological properties from medicine transferred for 3 - 5 minutes. After the termination of the procedure, the light source is switched off and the medication is taken away from the cylinder. Figure 1 shows a part of the device-laser-light guide emitter of the "device for transfer of pharmacological properties of a drug to the patient's body" in which the drug is placed. The height of the cylinder is $12 \mathrm{~cm}$, the diameter is $10 \mathrm{~cm}$ and the number of turns of the fiber optic waveguide around the cylinder is 12 , which is equal in height to 5 $\mathrm{cm}$. 


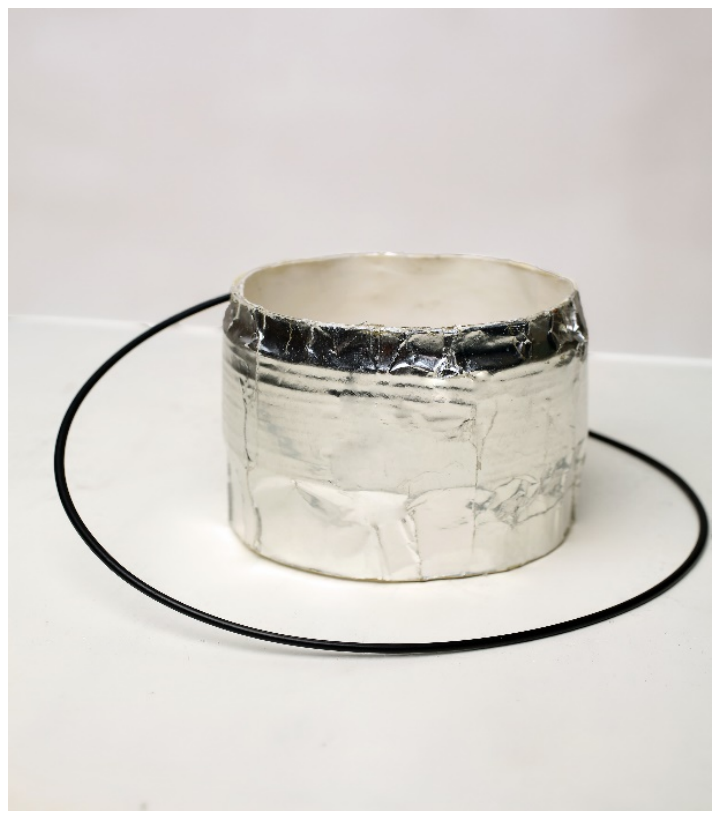

Figure 1. Laser-light guide emitter of the "device for transfer of pharmacological properties of a drug to the patient's body".

\subsection{Investigations}

The research design included the identification of viral infection and the viral load using real-time PCRtests. A predictor of a positive response to antiviral therapy is a decrease in the viral load in the blood of patients to undetectable levels as the result of the therapy, which may indicate the disappearance of the virus from the patient's body.

To determine the degree of fibrosis in the liver tissue, liver ultrasound elastography was performed. Fibrosis is a precursor to cirrhosis and establishing the severity of liver fibrosis helps predict liver-related morbidity and mortality and emergence of complications of liver disease. The test uses sound waves to measure the stiffness of liver tissue. Stiffness is a sign of fibrosis. According to Metavir score it ranges from 3.5 to more than 14.0 where the last is the marker of developed cirrhosis of the liver. The efficiency of the therapy was determined by the results of viral load detection during the therapy by PCR and liver elastography data.

In a group of patients with Covid-19 the study included PCR tests for detection of COVID-19. The lungs of the patients were examined by multi-spiral computer tomography (MSCT) before and at different stages of the treatment. In addition, various biochemical tests were applied as needed.

\section{3. "Medicament Testing" Technique}

The method of treatment of patients developed by the author starts with "medicament testing" (MT) method used to identify the virus in the patient's body and to find organs affected by the virus as well as in order to select a drug for a pa- 
tient [10]. In order to identify viruses in the patient's body using MT method, the specialist uses hepatitis B and C viruses nosodes as well as RNA-dependent RNA-polymerase of the Covid-19 virus. MT was carried out by the expert with 30 years' experience using Akuport M1+ apparatus (KINDLING, Germany) [11].

\section{Results}

All patients involved in the study composed the groups with verified diagnoses of various infections. The treatment and follow-up of the patients with CHBV infection was carried out from 2010 to 2021 . The first stage of the work with the group of CHBV patients ( 3 patients, ages 30 - 53; males) included examination of the patients by "medicament testing" for the purpose to identify the affected organs as well as to identify the hepatitis B virus in different organs and systems of the body. In the next stage, the patient was lying on the couch in the supine position and the patient was exposed to the DTIM therapy. In the group of patients with CHBV infection the Lamivudine (400 mg), was used. The developed therapy regimen assumes effects on three or four organs. The time interval between sessions was 7 - 10 days. The results of the conducted therapy are presented in Table 1.

The data presented in the table demonstrate that in the group of patients with the $\mathrm{CHBV}$, there was a long-term stable decrease in the viral load to a level below there commended level for antiviral therapy. A decrease in virus replication in liver tissue was accompanied by a regression of the process of fibrosis and restoration of the liver structure, what was reflected in the data of ultrasound elastography. In two patients, the exacerbation of the disease in the third year of observation accompanied by an increase in the viral load to level recommended for the antiviral therapy only required a single exposure with the use of Lamivudine in the emitter field. The only side effect from the use of drugs in the emitter field was weakness, which resolved during the next two days after therapy.

The treatment and follow-up of the patients with CHCV infection was carried out from 2012 to 2018 . The process of therapy in the group of patients with

Table 1. The results of therapy of patients with CHBV infection.

\begin{tabular}{|c|c|c|c|c|c|c|c|c|c|}
\hline Patient & Investigations & $\begin{array}{l}\text { Before } \\
\text { treatment }\end{array}$ & $\begin{array}{c}\text { Follow up } \\
4 \text { weeks }\end{array}$ & $\begin{array}{l}\text { Follow up } \\
24 \text { weeks }\end{array}$ & $\begin{array}{l}\text { Follow up } \\
\text { one year }\end{array}$ & $\begin{array}{l}\text { Follow up } \\
\text { two years }\end{array}$ & $\begin{array}{l}\text { Follow up } \\
\text { three years }\end{array}$ & $\begin{array}{l}\text { Follow } \\
\text { up four } \\
\text { years }\end{array}$ & $\begin{array}{c}\text { Follow } \\
\text { up ten } \\
\text { years }\end{array}$ \\
\hline \multirow[t]{2}{*}{1} & PCR (cop/ml) & 13,400 & 3540 & 2380 & 229 & 1500 & 3000 & 420 & 12 \\
\hline & Liver elast. & 7.9 & 5.3 & 4.73 & 3.5 & 4.4 & 6.1 & 4.1 & 5.8 \\
\hline \multirow[t]{2}{*}{2} & PCR (cop/ml) & $2,700,000$ & 5500 & 446 & abs & 781 & 10,270 & 261 & abs \\
\hline & Liver elast. & 5.3 & 4.73 & 4.4 & 4 & & 6.3 & 6.1 & 6.1 \\
\hline \multirow[t]{2}{*}{3} & PCR (cop/ml) & $2,000,000$ & & 500 & & 2500 & 200 & & abs \\
\hline & Liver elast. & 8.2 & & 6.2 & & 6.2 & 5.3 & & 3.2 \\
\hline
\end{tabular}


CHCV (3 patients, ages 24 - 70, female/male-2/1) was performed identically to the one described above and Daclatasvir (400 mg) and Sofosbuvir (90 mg) were used for the therapeutic purposes [12]. The information on the therapy is presented in Table 2.

According to the table data, in the group of patients with $\mathrm{CHCV}$, the therapy process took one month in comparison with the traditional treatment regimen, which takes from 3 to 6 months [13]. The termination of virus replication was accompanied by the termination of the fibrosing process and the restoration of the structure of the liver parenchyma, which was confirmed by the data of liver ultrasound elastography. No further exacerbation of the process was observed in any patient in the future. During the therapy, patients of both groups did not take antiviral drugs orally. The only side effect from the use of drugs in the emitter field was weakness, which resolved during the next two days after therapy.

The examination and observation of the patients with Covid-19 were carried out in July-September 2020. The group of patients with COVID-19 included 12 patients (ages 14 - 64, female/male-10/2) The condition of the patients was defined as mild in 8 patients and moderate severity in four patients. For the purpose of therapy of this group of patients, Copegus (Ribavirin) (La Roshe) in tablets was used [14]. The procedure was identical to the protocol developed for CHBV and CHCV patients with one difference, namely, all patients with COVID19 had a single DTIM procedure since in one session all organs in which Ribavirin was tested during MT were exposed to DTIM. Each patient was closely observed every day. The effect of the exposure with Ribavirin was analyzed and showed that 24 hours after the procedure no coronavirus was detected in the patients any more. The conclusion about the positive effect of the conducted therapy was based on the positive dynamics of the patient's condition, laboratory tests and the dynamics of MSCT of the lungs carried out in patients after the therapy. A negative response to the nosode of RNA-dependent RNA-polymerase and Ribavirin tablets according to MT results also indicated the absence of Covid-19 in the patient's body.

Table 2. Results of therapy of patients with CHCV infection.

\begin{tabular}{cccccc}
\hline Patient & Investigations & $\begin{array}{c}\text { Before } \\
\text { treatment }\end{array}$ & $\begin{array}{c}\text { Follow up } \\
\text { four weeks }\end{array}$ & $\begin{array}{c}\text { Follow up } \\
12 \text { weeks }\end{array}$ & $\begin{array}{c}\text { Follow up 6 } \\
\text { years }\end{array}$ \\
\hline 1 & PCR (cop/ml) & 5600 & abs & abs & abs \\
& Liver elast. & 7.5 & 5.3 & 3.0 & 3 \\
2 & PCR (cop/ml) & 76,000 & 5500 & abs & abs \\
& Liver elast. & 6.2 & 4.73 & 4.5 & 4 \\
& PCR (cop/ml) & $2,360,000$ & abs & abs & abs \\
& Liver elast. & 7.5 & 4.5 & 4.0 & 4.0 \\
\hline
\end{tabular}




\section{Discussion}

It was the first time when French mathematician Elie Cartan (1922) introduced the term torsion field to the Physician Science. Later, this theory was confirmed in the studies of other researchers [15]. A laser is a device, which produces intense, monochromatic, coherent, and highly collimated beam of light and involves visible red and near infrared (NIR) portions of the electromagnetic spectrum (390 - $1600 \mathrm{~nm}$ and 1013 - $1015 \mathrm{HZ}$. Light in physical optics is an electromagnetic radiation with the boundaries of the spectral range occupied by the light ranging from $310 \mathrm{~nm}$ to $1100 \mathrm{~nm}$. Light is created in many physical processes in which charged particles participate and its sources are, among others, stimulated emission of lasers [16]. Famous Russian astrophysicist N. Kozyrev, the author of several scientific theories, studying the distribution of light radiation of various stars, discovered some phenomena, which he described in his works [17]. Being based on the results of his research, scientists of the Institute of Space Anthropoecology of the Siberian Branch of the Academy of Russia developed a "device for remote transferring of information from the medicine to the human body (DTMP)" [9]. The Russian scientists have studied the properties of the device and described the findings of their in vitro and in vivo experiments [18]. Their patent also describes the findings on transmission of properties of a number of medicaments into the patient's body. The objects of the research described in the patent are patients with diabetes type 2. To demonstrate the phenomenon, insulin was placed into the field generated by the device and insulin properties are transmitted to the patient's body. This resulted by the reduction of the patient's blood glucose level. The other case describes the results of the procedure in patient with heart rhythm disorders when adrenaline was placed in the device field, which resulted by normalization of the heart rhythm. Depending on the rotation of the waveguide around the axis of the cylinder, to the right or to the left, various biological effects have observed. The rotation of the waveguide to the right side provides an increase in the synthesis of protein and carbohydrates in the studied tissue, and the rotation of the waveguide to the left side increases the mitotic activity in the tissues [19]. Since the interests of the author of this publication are focused on viral diseases, patients with chronic hepatitis B and C viral infections were involved as the research objects [20]. Some modifications have been made in the Russian patent [21].

In the group of patients with $\mathrm{CHBV}$, for the purpose of therapy, the drug Lamivudine was used. Lamivudine (2',3'-dideoxy-3'-thiacytidine, commonly called $3 \mathrm{TC}$ ) is a potent nucleoside analog reverse transcriptase inhibitor (nRTI).

In the group of patients with $\mathrm{CHCV}$ for the purpose of therapy two antiviral medications Sofosbuvir and Daclatosvir were used. Sofosbuvir is a nucleotide analog that is a highly potent inhibitor of the NS5B polymerase in HCV. Daclatasvir is an inhibitor of the hepatitis $\mathrm{C}$ virus (HCV) non-structural protein $5 \mathrm{~A}$ (NS5A) replication complex.

As a result of careful selection of drugs used in the treatment of different viral 
diseases using the MT method, the author selectively selected Ribavirin for the treatment of patients with Covid-19. Ribavirin is an antiviral drug which has proved to be efficient in therapy of MERS-Cov-2013 [14]. Ribavirin is known to inhibit inosine monophosphate dehydrogenase, which leads to a marked decrease in intracellular guanosine triphosphate levels that, in turn, is accompanied by suppression of the synthesis of viral RNA and virus-specific proteins. Ribavirin selectively inhibits viral RNA synthesis without suppressing RNA synthesis in normally functioning cells [22]. In the opinion of the author, it is extremely important to choose a drug for the therapy with the use of DTIM. All of these drugs are inhibitors of structures vital for the replication of the viruses, which actually provided the results of the therapy.

Apparently, when the drug is placed into the laser-light guide emitter, with the laser turned on, a certain field being formed inside the laser-light guide emitter causes vibration to the molecules of the drug. This field, undoubtedly, is a component of electromagnetic radiation of laser radiation, which is formed as soon as the direction of the flow of electric charges, passing along the laser lightguide emitter around its axis to form a circle, is changed. Further, under the influence of the generated by the emitter field, the drug pharmacological properties in the form of an imprint of the crystal lattice of the drug's chemical structure are transmitted downwards along the course of the emitter's spiral. Interacting with the electromagnetic field of the virus, the electromagnetic imprint of the drug, apparently, begins to exert its therapeutic effect, which destroys the virus in the patient's body. The only side effect observed when using this technology was weakness appearing in patients immediately after exposure, which lasted for 2 days. No other effects from the use of drugs with DTIM were observed.

The ability of various pathogens to emit electromagnetic fields was shown by number of scientists: Nobel Prize winner Luc Montagnier in 2009 described the phenomenon of emitting of specific radio waves by diluted DNA from pathogenic bacteria (M. pirum and E. coli) and virus species (HIV RNA in the blood of AIDS patients). The group of Russian scientists in 1966 registered the discovery of "The phenomenon of the intercellular distant electromagnetic interactions in the system of two tissue cultures". In 2005 the group of scientists from the University of California in San Diego published the article entitled "Ion channels enable electrical communication in bacterial communities" [23] [24] [25] [26].

Apparently, the effects described in this article can be explained by phenomenon of interaction between two objects: the imprint of the crystal lattice of the chemical structure of organic substance (drug) placed inside emitter and the electromagnetic field of the pathogen itself, which in the future leads to the destruction of the virus in the target organ of the patient. It is an obvious fact that it is impossible to apply the parameters recommended for describing laser radiation in articles, since low-level lasers in such an interpretation have not been used anywhere before. 


\section{Conclusion}

Our research has shown that the use of the "device for transfer of the pharmacological properties of a drug into the patient's body" is a new alternative method for the use of approved drugs that provides a safe and quick effect on pathogenic human viruses. Ribavirin used into the laser-light-guide-emitter of DTIM is the medicament of choice in the treatment of COVID-19 patients, which provides the quick elimination the virus from the patients' body. The results of the therapy of $\mathrm{CHCV}$ infection patients with approved antiviral medicaments placed into the laser-light-guide-emitter of the DTIM showed reduction of the therapy duration in comparison with the traditional therapy. In case of CHBV infection, it turned out that the exposure of approved antiviral drugs with DTIM decreases persistently the virus replication, resulted in the process stabilization and prevented development of cirrhosis in the patients suffered from CHBV infection. The use of traditional antiviral drugs with the application of DTIM deprives them of side and adverse effects and allows patients to tolerate the therapy more easily.

\section{Conflicts of Interest}

The author declares no competing interests.

\section{Funding Sources}

This research did not receive any specific grant from funding agencies in the public, commercial, or not-for-profit sectors.

\section{References}

[1] Fonseca, A.S., Moreira, T.O., Paixão, D.L., Farias, F.M., Guimarães, O.R., De Paoli, S., Geller, M. and De Paoli, F. (2010) Effect of Laser Therapy on DNA Damage. Lasers in Surgery and Medicine, 42, 481-488. https://doi.org/10.1002/lsm.20921

[2] Tuby, H., Maltz, L. and Oron, U. (2014) Induction of Autologous Bone-Marrow Stem Cells by Low-Level Laser Therapy Has Beneficial Effects on the Kidneys PostIschemia-Reperfusion Injury in the Rat. Journal of Biomedical Science and Engineering, 7, 453-463. https://doi.org/10.4236/jbise.2014.78048

[3] Mussttafa, R.A., Jenkinsa, D.F. and Jhab, A.N. (2019) Assessing the Impact of Low Level Laser Therapy (LLLT) on Biological Systems: A Review. International Journal of Radiation Biology, 95, 120-143. https://doi.org/10.1080/09553002.2019.1524944

[4] Huang, Y.-Y., Nagata, K., Tedford, C.E. and Hamblin, M.R. (2014) Low-Level Laser Therapy $(810 \mathrm{~nm})$ Protects Primary Cortical Neurons against Excitotoxicity in $\mathrm{Vi}$ tro. Journal of Biophotonics, 7, 656-664. https://doi.org/10.1002/jbio.201300125

[5] Di Giacomo, P., Orlando, S., Dell'ariccia, M. and Brandimarte, B. (2013) Low-Level Laser Therapy: Laser Radiation Absorption in Biological Tissues. Applied Physics $A, 112,71-75$. https://doi.org/10.1007/s00339-012-7204-z

[6] Silveira, P.C., da Silva, L.A., Fraga, D.B., Freitas, T.P., Streck, E.L. and Pinho, R. (2009) Evaluation of Mitochondrial Respiratory Chain Activity in Muscle Healing by Low-Level Laser Therapy. Journal of Photochemistry and Photobiology B: Biology, 95, 89-92. https://doi.org/10.1016/j.jphotobiol.2009.01.004 
[7] Canuto, K, Sergio, L., Guimarães, O., Geller, M., Paoli, F. and Fonseca, A. (2015) Low-Level Red Laser Therapy Alters Effects of Ultraviolet C Radiation on Escherichia Coli Cells. Brazilian Journal of Medical and Biological Research, 48, 939-944. https://doi.org/10.1590/1414-431X20154459

[8] Burduli, N.M. and Krifaridi, A.S. (2009) Effect of Low-Intensity Laser Radiation on the Function of Vascular Endothelium in Patients with Chronic Viral Hepatitis. Med(Russia), 87, 49-52.

[9] Kaznacheev, V.P, Trofimov, A.V and Shatarin, A.Y. (2001) Device for Remote Information Transmission from Medicinal Preparation to Human Organism. RU Patent No. $2163491 \mathrm{C} 2$.

[10] Oliveira, A. (2016) Electroacupuncture According to Voll: Historical Background and Literature Rreview. The Journal of Acupuncture and Oriental Medicine, 3, 5 10. https://www.researchgate.net/publication/290437736

[11] Kindling BioEnergetic. http://www.kindling.de/eng/elektroakupunktur/index.html

[12] Sulkowski, M.S, Gardiner, D.F, Rodriguez-Torres, M., Reddy, K.R, et al. (2014) Daclatasvir plus Sofosbuvir for Previously Treated or Untreated Chronic HCV Infection. New England Journal of Medicine, 370, 1469. https://doi.org/10.1056/NEJMx140011

[13] World Gastroenterology Organisation (2015) World Gastroenterology Organisation Practice Guideline.

https://www.worldgastroenterology.org/UserFiles/file/guidelines/hepatitis-b-english -2015.pdf

[14] Omrani, S., Saad, M., Baig, K., Bahloul, A., Abdul-Matin, M., Alaidaroos, A.Y., et al. (2014) Ribavirin and Interferon alfa-2a for Severe Middle East Respiratory Syndrome Coronavirus Infection: A Retrospective Cohort Study. Lancet Infectious Diseases, 14, 1090-1095. https://doi.org/10.1016/S1473-3099(14)70920-X

[15] Laércio Dias, L. and Moraes, F. (2005) Effects of Torsion on Electromagnetic Fields. Brazilian Journal of Physics, 35, 636-640. https://doi.org/10.1590/S0103-97332005000400009

[16] Sliney, D. (2016) What Is Light? The Visible Spectrum and Beyond. Eye, 30, Article 222-229. https://doi.org/10.1038/eye.2015.252

[17] Kozyrev, N. A. (1971) On the Possibility of Experimental Investigation of the Properties of Time. In: Time in Science and Philosophy, Prague, 111-132.

[18] Kaznacheev, V.P., Kiselnikov, A.A. and Mingasov, I.F. (2005) Noospheric Ecology and Human Economics: Problems of the "Sphinx of the XXI Century. Novosibirsk, 447 p. [in Russian].

[19] Kaznacheev, V.P. and Trofimav, A.V. (2004) Essays on the Nature of Living Matter and Intelligence on Planet Earth: Problems of Cosmoplanetars. Anthropoecology. In: Kaznacheev, V.P. and Trofimov, A.V., Eds., Science, 293-312. [in Russian] https://web.archive.org/web/20170530181521/http://elib1.ngonb.ru/jspui/handle/N GONB/676

[20] Djumaeva, N.E. (2000) Electroacupucture Diagnosis by Voll and Bio-Information Methods of Therapy in Different Group of Patients with Chronic Hepatitis B Infection. Ph.D Thesis, Scientific-Research Institute of Epidemiology, Microbiology and Infectious Diseases, Tashkent.

[21] Djumaeva, N. and Djumaeva, L. (2005) Method for the Treatment of Somatic Diseases. Patent of Uzbekistan No. IDP 03033.

[22] Dixit, N.M. and Perelson, A.S. (2006) The Metabolism, Pharmacokinetics and Me- 
chanisms of Antiviral Activity of Ribavirin against Hepatitis C Virus. Cellular and Molecular Life Sciences CMLS, 63, 832-842. https://doi.org/10.1007/s00018-005-5455-y

[23] Montagnier, L., Aäissa, J., Ferris, S., Montagnier, J.-L. and Lavalléee, C. (2009) Electromagnetic Signals Are Produced by Aqueous Nanostructures Derived from Bacterial DNA Sequences. Interdisciplinary Sciences. Computational Life Sciences, 1, 8190. https://doi.org/10.1007/s12539-009-0036-7

[24] Kaznacheev, V.P., Mihaylova, M.P. and Shurin, S.P. (1966) The Phenomenon of Intercellular Distant Electromagnetic Interactions in the System of Two Tissue Cultures. State Register of Discoveries of the USSR No. 122. [In Russian]

[25] Kaznacheev, V.P. and Mihaylova, M.P. (1981) Ultra-Weak Radiations in Intercellular Interactions. Science, Novosibirsk. [In Russian]

[26] Prindle, A., Liu, J., Asally, M., San, L., Garcia-Ojalvo, J. and Süel, G.M. (2015) Ion Channels Enable Electrical Communication in Bacterial Communities. Nature, 527, 59-63. https://doi.org/10.1038/nature15709 